REVISTA DE DERECHO UNED, NÚM. 23, 2018

\title{
EL «VIGILANTISMO»COMO REFLEJO DEL FRACASO DEL SISTEMA JURÍDICO-PENAL ESTADOUNIDENSE EN LOS AÑOS SETENTA: ANÁLISIS DE LA PELÍCULA «DEATH WISH» (EL JUSTICIERO DE LA CIUDAD)
}

\author{
«VIGILANTISM»AS A REFLEX OF THE FAILURE \\ OF THE AMERICAN CRIMINAL JUSTICE SYSTEM IN THE 70'S: \\ ANALYSIS OF THE MOVIE «DEATH WISH»

\section{ManUel-ÓsCar REMESEIRo FERNÁNDEZ} \\ Investigador (doctorando) en la Escuela de Doctorado \\ de la Universidad Nacional de Educación a Distancia (UNED), \\ programa en Derecho y Ciencias Sociales
}

Resumen: El Vigilantismo es una corriente ideológica que propugna el derecho a la autodefensa de los individuos cuando el Estado no es capaz de proporcionársela de manera eficaz. Experimentó un considerable auge en los Estados Unidos a partir de los años setenta, presentándose como una alternativa válida en la lucha contra la elevada criminalidad. El Vigilantismo defiende una visión eminentemente punitiva de la Justicia. La película «Death Wish», de Michael Winner (Paramount Pictures, 1974), y protagonizada por Charles Bronson, en el papel de Paul Kersey, retrata de forma certera esta doctrina.

Palabras clave: Vigilantismo, Sistema jurídico penal, Criminalidad, Respuesta punitiva, Control social.

${ }^{1}$ Licenciado en Derecho por la Universidad de Alcalá. Máster en Seguridad (Seguridad Interior del Estado) por la UNED. Investigador (doctorando) en la Escuela de Doctorado de la Universidad Nacional de Educación a Distancia (UNED), programa en Derecho y Ciencias Sociales. 
Abstract: Vigilantism is an ideological stream that advocates the right to self-defense of the individuals when the Government is unable to provide it effectively. It underwent a considerable boom in the United States from the 1970s, posing as a valid alternative in the fight against high rates of criminality. Vigilantism defends an essential punitive vision of Justice. The film «Death Wish», directed by Michael Winner (Paramount Pictures, 1974), with Charles Bronson, playing the role of Paul Kersey, is an acute portrait of this doctrine.

Keywords: Vigilantism, Criminal justice system, Criminality, Punitive response, Social control.

Recepción original: 03/04/2018

Aceptación original: 20/09/2018

Sumario: Introducción.-I. Análisis crítico del filme: Las grandes cuestiones que se plantean al espectador. I.A. La pobreza, el delito y la deshumanización del delincuente. I.B. El miedo a la delincuencia. I.C. El control de armas. I.D. La respuesta punitiva. I.E. La organización del espacio urbano. I. F. las drogas.-II. La evolución del perfil psicológico del protagonista.-III. El misterio de los personajes ausentes.-IV. Conclusiones.-V. Bibliografía.

\section{INTRODUCCIÓN}

Comenzaremos nuestra exposición definiendo qué es el Vigilantismo (Vigilantism). La West's Encyclopedia of American Law nos ofrece varias acepciones del término: «Tomarse uno la justicia por su mano y tratar de aplicar la ley de acuerdo con la propia interpretación de lo justo e injusto. Acción llevada a cabo por un grupo de voluntarios autoorganizados, con el propósito de proteger un interés común: tal como la libertad, la propiedad o la integridad física. Acción llevada a cabo por un individuo, o un grupo, para protestar contra una ley existente. Acción llevada a cabo por un individuo, o un grupo, para promover el endurecimiento de una ley más allá de lo establecido por el legislador. En el supuesto de inexistencia de un cuerpo de seguridad, constituido y fiable, fuerza de seguridad privada con sus propias normas. $\aleph^{2}$

De la anterior definición (más concretamente, del conjunto de sus diversas acepciones), podemos inferir algunas de las característi-

2 WEST'S ENCYCLOPEDIA OF AMERICAN LAW. Término: «Vigilantism». https://legal-dictionary.thefreedictionary.com/Vigilantism [fecha de consulta 20-082018]. (Trad. Autor.) 
cas esenciales del Vigilantismo, como corriente ideológica, en la esfera del derecho penal:

\section{a) Suplantación del papel del Estado como garante del orden público y monopolizador del ejercicio de la violencia}

El Vigilantismo propugna el derecho a la autodefensa de los individuos cuando el Estado no es capaz de proporcionársela de manera eficaz. En estos casos, los defensores de esta teoría sostienen que el Gobierno ha incumplido su «Contrato Social» con los ciudadanos y, por tanto, ellos recuperan para sí el derecho de ejercer directamente la acción de la Justicia. Así resume el Profesor Timothy O. Lenz, especialista en la materia, este postulado básico del Vigilantismo:

«Los ciudadanos ceden al gobierno algunos poderes, pero se reservan ciertos derechos. Por ejemplo, ceden su potestad de perseguir y castigar los actos delictivos a cambio de que el gobierno asuma la responsabilidad de proveerles de la adecuada seguridad ciudadana. Bien es verdad que, los ciudadanos, ya sea a nivel colectivo o individual, tienen el derecho de recuperar para sí esa potestad cuando el gobierno declina su ejercicio o es incapaz de facilitarles orden público, seguridad o justicia.» ${ }^{3}$

El problema que se suscita, en este supuesto, es dilucidar cuándo el Estado «abdica» del ejercicio de su responsabilidad como garante de la seguridad pública y «cede» el monopolio de la violencia represiva a estos grupos de vigilantes. El Profesor William C. Culberson nos señala, algunas pistas, al respecto:

«Si el Gobierno no se encontraba suficientemente asentado u organizado para controlar, o castigar, a los infractores del orden público, los líderes comunitarios del Viejo Oeste, a menudo, tomaban cartas en el asunto, y aplicaban la violencia contra la violencia. El Vigilantismo surge, pues, para satisfacer las necesidades de aplicación práctica de la justicia en ausencia de instituciones que regulen el orden social. Estas prácticas resolvían un problema de orden público, a la vez que servían de advertencia de que las facilidades de establecimiento en los nuevos territorios (para los nuevos colonos) no suponían, en modo alguno, una oportunidad para la erosión de los valores vinculados con llevar una existencia moral, así como con la protección de la propiedad privada cuando el Gobierno no quería, o no podía, hacerlo.» ${ }^{4}$

${ }^{3}$ LENZ, T., "Conservatism in America Crime Films», Journal of Criminal Justice and Popular Culture, n. ${ }^{\circ}$ 12, 2005, p. 134. (Trad. Autor.)

${ }^{4}$ CULBERSON, W., Vigilantism: Political History of Private Power in the United States, Greenwood, Nueva York 1990, p. 3. (Traducción, y nota entre paréntesis, del Autor.) 
Para Culberson, por tanto, los factores clave para esta cesión de soberanía son, fundamentalmente: la falta de organización e implementación de un aparato jurídico-penal estatal y la existencia, en la sociedad, de un sólido código de valores comunes compartidos, teóricamente basados en el «derecho natural», y que tiende a mantener el «statu quo» imperante. Una consecuencia muy grave de lo anterior es que la ley es aplicada, por sujetos no preparados para ello, según criterios personales de interpretación; lo que entraña elevadísimos grados de arbitrariedad e inseguridad jurídica que contrastan con la defensa de la libertad individual propugnada por el Vigilantismo. Además, para el ejercicio activo de esas competencias, autoarrogadas, es imprescindible el empleo de la fuerza y ello implica la necesidad de que los individuos gocen del derecho a portar armas.

\section{b) Derecho a portar armas por parte de los ciudadanos}

En el imaginario colectivo norteamericano, supone la exaltación de los ideales mitificados de la época de la colonización. De ahí, que constituya otro de los pilares del Vigilantismo: el «sagrado» derecho de los hombres a portar armas, reconocido en la Segunda Enmienda de la Constitución norteamericana, aprobada el 15 de diciembre de 1791:

«Una milicia popular bien organizada es necesaria para la seguridad de un Estado libre; por tanto, el derecho del pueblo a portar y utilizar armas no debe ser cuestionado.» ${ }^{5}$

Bien es verdad, que el Vigilantismo hace una interpretación interesada del texto legal puesto que éste fue promulgado en un contexto histórico muy concreto: el de la reciente independencia de los Estados Unidos. (1776). Entonces, la gran dispersión de la población, la ausencia de fuerzas del orden en extensos territorios, excepto en algunos enclaves del ejército, los constantes enfrentamientos con los nativos norteamericanos, y, la presencia de bandas armadas de diversa índole, hacían necesaria esta enmienda. Las circunstancias eran, por tanto, muy diferentes a las actuales. Sin embargo, esa reivindicación del pasado, de una supuesta Arcadia feliz, se hace patente en la película, que vamos a estudiar, cuando el protagonista debe viajar, por motivos de trabajo, a la ciudad de Tucson (Arizona).

${ }^{5}$ ESTADOS UNIDOS DE AMÉRICA, Constitución de los Estados Unidos, Segunda enmienda. Instituto de información legal. Universidad de Cornell. N.Y. https://www.law.cornell.edu/constitution/second_amendment [Fecha de consulta 12-05-2017]. (Trad. Autor.) 
La América profunda, se nos presenta, entonces, como aquel lugar dónde las esencias perduran, la naturaleza es todavía virgen y los niveles de delincuencia son muy bajos o prácticamente inexistentes.

El siguiente fragmento de un diálogo entre el protagonista, Paul Kersey, y su cliente, el constructor y agente inmobiliario de Tucson, el señor Jainchill, es una prueba evidente de que amplios sectores de población norteamericana identifican la posesión y el empleo de las armas de fuego con la libertad y la seguridad de los miembros de la comunidad:

«Jainchill. (...) Pero este es un territorio de armas. Ya sé que en Nueva York no se puede llevar ni una pequeña pistola, pero aquí todo el mundo tiene, por lo menos, una. Y le diré una cosa... Al contrario que en su ciudad, aquí se puede pasear por calles y parques, incluso de noche. ${ }^{6}$

Volveremos sobre este controvertido asunto del derecho a portar armas, con mayor detalle, más adelante, en el apartado I.C. de este artículo, cuando estudiemos las grandes cuestiones que se plantean al espectador en la película.

\section{c) Desconfianza en la burocracia estatal y defensa de la libertad individual}

Otra característica típica del Vigilantismo es su falta de confianza en el Estado, que se entiende como una «carga» y no se percibe como agente vertebrador de la sociedad y árbitro neutral de la convivencia. La burocracia, para esta corriente de pensamiento, no es más que un mecanismo del poder para coartar la libertad de acción del ciudadano. El Profesor Mc Kenna lo explica de esta manera:

«Desde mi punto de vista, la definición de «vigilante» hace referencia a un individuo que es producto de la sociedad moderna y experimenta, en su quehacer diario, un fuerte sentimiento de desamparo ante una serie de obstáculos externos, un exceso de trámites burocráticos que no dejan de estar presentes a lo largo de su vida. La figura del vigilante en "Death Wish" podría ejemplificar al individuo anónimo que ha sido despersonalizado por una ineficaz, e invariablemente liberal, burocracia y que se encuentra ahora (tras la muerte de su mujer), a través de los medios más crueles y violentos, defendiendo, una vez más, su personalidad. Pero este tipo de libertad, incluso en su variante de ficción, es sumamente conservadora. Kersey (al principio de la película) es una víctima, un "alma cándida"

${ }^{6}$ WINNER, M., Death Wish, Paramount Pictures, Los Ángeles, 1974. 
que cree en los cuentos de hadas sobre resocialización, clemencia y

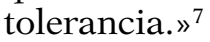

Paul Kersey, un liberal convencido, al principio de la película, evoluciona hacia posturas ideológicamente antagónicas tras comprobar como aquel Estado, al que ha venido sosteniendo con sus impuestos, a lo largo de los años, es incapaz de encontrar a los asesinos de su esposa y violadores de su hija. Y cuando decide actuar, por su cuenta, ejerciendo su libertad como individuo es ese mismo Estado el que le acaba deteniendo.

\section{d) Enfoque netamente punitivo de la aplicación de las normas}

El Vigilantismo defiende una visión eminentemente punitiva de la Justicia. El aumento de la criminalidad producido en los EE.UU., sobre todo desde comienzos de los años 60 , obedeció a una serie de causas complejas e interrelacionadas, tales como: los cambios en el diseño de los espacios urbanos; el incremento de las desigualdades por la disminución de los fondos para políticas sociales (la época de fuerte auge de la criminalidad coincide con la guerra que los Estados Unidos no consiguieron ganar, Vietnam, pero que supuso un gasto de miles de millones de dólares); la crisis del petróleo de 1973 y sus graves implicaciones económicas; los estragos ocasionados por la progresiva introducción de la droga en las grandes ciudades, especialmente, en los barrios más desfavorecidos; y la continuación de las fuertes tensiones y disturbios raciales, sobre todo en los estados del sur. A pesar de lo cual, la interacción entre esos múltiples factores, potencialmente criminogénicos, no está suficientemente demostrada, para algunos expertos, tal y como sugiere el Profesor James Q. Wilson:

«Según un estudio sobre las tasas de criminalidad en varias ciudades, llevado a cabo por Arnold Barnett, y su equipo de investigadores, en el Instituto Tecnológico de Massachusetts, el incremento de la tasa de asesinatos, durante los años 60 , fue más de diez veces superior al que sería justificable por el mero incremento de la población. Aparentemente, gran número de fuerzas complejas estaban interactuando en todas las grandes ciudades. Por ejemplo, Detroit pasó a ser conocida, erróneamente, como la "capital mundial del asesinato" (dudosa distinción que hoy corresponde a la ciudad de Atlanta). El incremento del número de asesinatos fue, más o menos, el mismo en las 50 ciudades más grandes (se dobló entre 1963 y 1971). Clara-

${ }^{7}$ Mc KENNA, T., Art, Literature and Culture from a Marxist Perspective, Palgrave Macmillan, Londres 2015, p. 129. (Traducción, y notas entre paréntesis, Autor.) 
mente, amplias fuerzas de alcance nacional estaban implicadas, pero nadie sabe, a ciencia cierta, cuáles eran. Los resultados resultaban aterradores: si las tasas de asesinatos se mantenían constantes, a ese nivel, entonces, un niño nacido en Detroit, en 1974, y que pasase toda su vida en la ciudad, tenía 1 entre 35 posibilidades de ser asesinado (...) En los niveles de los años 70, Barnett apuntó que un niño, nacido en una gran ciudad americana, y que permaneciese en esta toda su vida, tenía más posibilidades de morir asesinado de las que habría tenido un soldado estadounidense, de morir en combate, en la Segunda Guerra Mundial.» ${ }^{8}$

Las fuerzas ideológicas más reaccionarias aprovechan la situación para reivindicar los modelos penales basados en la respuesta punitiva, en el castigo por encima de la resocialización del individuo. Y no lo hacen de forma inocente, sino sabedoras de que las restricciones presupuestarias, provocadas por la recesión económica, ya no permiten el sostenimiento de parte del entramado burocrático y asistencial del complejo jurídico penal y de que los contribuyentes de menor poder adquisitivo son cada vez más conscientes de ello. Esto, provoca, paradójicamente, el apoyo indirecto de las clases trabajadora y media a un modelo jurídico penal que criminaliza, y persigue, a las capas más desfavorecidas de la sociedad. Lo describe, brillantemente, el sociólogo del Derecho, David Garland:

«Los cambios demográficos, en la estratificación social y en las tendencias políticas llevaron a que importantes sectores de las clases trabajadora y media cambiaran su actitud respecto de muchas de estas políticas, comenzando a considerarlas como opuestas a sus intereses colectivos y a favor de grupos que no lo merecían y que eran cada vez más peligrosos. En este nuevo contexto político, las políticas welfaristas para los pobres se representaban de forma cada vez más marcada como lujos costosos que los contribuyentes que trabajaban duramente ya no podían solventar. ${ }^{9}$

Y los defensores del Vigilantismo son una parte muy representativa de estas fuerzas conservadoras. Así lo consideran los profesores Rosenbaum y Sederberg, de la Universidad de Pennsylvania:

«El contexto social del Vigilantismo se fundamenta en ciertos grupos que se creen poseedores de un interés legítimo en la conservación del actual sistema de valores (...) El Gobierno, entonces, es visto (con permiso de Marx) como «una manifestación superestructural del sistema de valores dominante en la base social». Las escalas de valores de esos grupos son relativamente estables y el Estado es percibido por ellos como un ente legitimador de esa escala (...) El

8 WILSON, J., Thinking about Crime, Basic Books, Nueva York 2013, p. 13. (Trad. Autor.)

9 GARLAND, D., La cultura del control, Gedisa, Barcelona 2005), p. 138.

(C) UNED. Revista de Derecho UNED, núm. 23, 2018 
"Vigilantismo de control de la delincuencia", el más extendido de todos los tipos de Vigilantismo, es aquél que se dirige contra las personas que se cree puedan estar perpetrando actos proscritos por el sistema legal formal. Por ejemplo, aquellos supuestos en que puedan resultar dañadas personas, o propiedades, privadas y en los que los malhechores eludan la acción de la justicia, bien sea por la ineficacia del Gobierno, la corrupción o la benevolencia del sistema jurídico penal. Esta forma de violencia del "establishment" llevada a cabo por individuos a título personal es la más comúnmente asociada a los "vigilantes" (...) Este tipo de acciones han sido, a menudo, organizadas y dirigidas, por representantes de las clases altas en comunidades afectadas por olas delictivas. Si bien, estos miembros del "establishment", han pretendido representar los valores de sectores sociales más amplios.» ${ }^{10}$

Para estos grupos de presión, la solución al aumento de criminalidad requiere, entre otras cosas, un fuerte incremento de la represión (la respuesta punitiva). El encarcelamiento de los delincuentes es el eje principal de esa respuesta y pasa a convertirse en un fin en sí mismo. Con un doble objetivo: castigar a quien vulnera la ley y mantenerlo apartado del resto de la sociedad, y servir como ejemplo disuasorio para otros posibles delincuentes potenciales. Pero sabemos que las cosas no funcionan así. El Profesor Kleiman, de la Universidad de California, en Los Ángeles, (U.C.L.A.), nos explica el porqué:

«Un modelo simplista del crimen sostendría que éste se comete solamente cuando la amenaza del castigo es insuficiente para contrapesar los beneficios de su perpetración. Esto, implicaría asumir que los delincuentes se comportan de manera perfectamente racional. Si así fuese, el delito podría ser eliminado, o casi, incrementando la amenaza del castigo, ya fuese en su severidad, en la probabilidad de su imposición, o en ambas.» ${ }^{11}$

Los hechos desmienten estas polémicas políticas y confirman, de este modo, el fracaso de este postulado del Vigilantismo. Así, por ejemplo, el incremento sostenido de la población penitenciaria de EE.UU. desde los años setenta no provocó, ni mucho menos, la correlativa disminución de las tasas de criminalidad. Tampoco lo lograron las cuantiosas inversiones en la lucha contra la delincuencia en general y el tráfico de drogas, en particular. A pesar de que más de dos millones y medio de norteamericanos viven encarcelados, y

10 ROSENBAUM, J., SEDERBERG, P., «Vigilantism: An Analysis of Establishment Violence» en Comparative Politics, n. ${ }^{\circ} 4$, 1974, pp. 541-570. (Trad. Autor.)

11 KLEIMAN, M., When Brute Force Fails, NCJRS 2005, Departamento de Justicia. Gobierno de los Estados Unidos de América, p. 44. https://www.ncjrs.gov/ pdffiles1/nij/grants/211204.pdf [fecha de consulta 21.08.2018]. (Trad. Autor.) 
las libertades civiles son recortadas, en aras de la seguridad colectiva, las tasas de criminalidad siguen siendo enormemente elevadas. Así lo manifestó, en el año 2010, John Dilulio, director de la Oficina de Iniciativas Comunitarias de la Casa Blanca durante el mandato del presidente George W. Bush:

«En el año 2010, hace ya 25 años que los Estados Unidos de América vienen realizando cuantiosas inversiones, públicas y privadas, en materia de control de criminalidad, endurecimiento de las sentencias penales y cambios en los estilos de vida personales para hacerlos más seguros. A pesar de todo ello, los índices de criminalidad no son menos elevados que los de hace 50 años. Y, en muchos lugares, son aún peores que cuando estalló la alarma social contra el crimen. Desde que la delincuencia ascendió a la cúspide de la agenda política federal, en los primeros años 60, las guerras de los sucesivos gobiernos, contra el crimen y las drogas, han sacrificado derechos y libertades civiles otrora sagrados. Hoy, cerca de dos millones y medio de estadounidenses viven encarcelados mientras decenas de millones lo hacen en urbanizaciones blindadas. ${ }^{12}$

\section{ANÁLISIS CRÍTICO DEL FILME: LAS GRANDES CUESTIONES QUE SE PLANTEAN AL ESPECTADOR}

«Death Wish» (traducido literalmente «Deseo de muerte») es el título original de la película que vamos a analizar en el artículo. Estrenada en el año 1974, fue dirigida por Michael Winner, y protagonizada por Charles Bronson. En España se tituló «El justiciero de la ciudad» y en Iberoamérica «El vigilante». Aunque una voz en off, al comienzo de la película, cambia el título por el de: «Justicia Callejera». Narra la historia de Paul Kersey, un arquitecto neoyorquino, de ideología liberal. Después de regresar de Hawái, tras pasar unas vacaciones con su esposa, y mientras se encuentra trabajando, tres delincuentes habituales asaltan su domicilio, violan a su hija y hieren gravemente a su mujer que fallece, poco más tarde, en el Hospital. Tras unas semanas, Kersey ve como la policía es incapaz de encontrar a los asesinos mientras su hija sufre un grave «shock» de estrés post-traumático. A la vez que atraviesa un período de duelo personal, dado lo acontecido, y preocupado por los elevados índices de criminalidad de la ciudad, Kersey sufre un atraco, (hace frente al atracador con un calcetín relleno de monedas), y logra poner en fuga el asaltante. Por motivos profesionales, debe desplazarse a Tucson

12 DILUliO, J., «Rethinking Crime-Again», Democracy: A Journal of Ideas, n. ${ }^{\circ} 16,2010$, pp. 46-57. http://www.democracyjournal.org/16/6739.php [fecha de consulta 14-05-2017]. (Trad. Autor.)

(C) UNED. Revista de Derecho UNED, núm. 23, 2018 
(Arizona). Allí, visita una galería de tiro con un cliente, el cual exalta las maravillas de la ciudad, en la que reinan la paz y el orden y dónde la gente va armada. Kersey retorna a Nueva York con un particular regalo en la maleta: un revólver del calibre 32. Revólver que utiliza, por primera vez, cuando sufre, de nuevo, un atraco mientras pasea por un parque cercano a su casa. Dispara contra el atracador y lo mata. Se convierte en El Vigilante y toma la determinación de no volver a dejarse intimidar. Tiene más encontronazos con delincuentes, a los que dispara y elimina. Sus «andanzas» llegan a oídos de la prensa y la policía se siente puesta en ridículo, tras ser aplaudidas las actuaciones del Vigilante por los medios de comunicación.

Una vez realizada la sinopsis de la película pasamos a estudiar algunos de sus aspectos, a nuestro juicio, más significativos.

\section{I.A. La pobreza, el delito y la deshumanización del delincuente}

Los años setenta fueron turbulentos para los Estados Unidos en los planos económico, político y social. Los niveles de pobreza y descontento populares aumentaron de forma muy significativa. Howard Zinn, historiador crítico norteamericano, contextualiza así la década:

«Una gran parte del descontento general probablemente se debía a la situación económica de la mayoría de los americanos. La inflación y el desempleo estaban en aumento desde 1973. En otoño de 1975, una encuesta del New York Times realizada entre 1.559 personas, junto con las entrevistas realizadas a sesenta familias en doce ciudades, mostraban «una disminución substancial del optimismo respecto al futuro». La encuesta descubría que incluso la gente con ingresos altos «no es tan optimista ahora como en los años anteriores, lo cual indica que el descontento se está desplazando de los niveles de ingresos bajos o medios a los niveles de ingresos altos». Las estadísticas del gobierno indicaban las razones. El índice de desempleo, $5,6 \%$ en 1974 , se había elevado a $8,3 \%$ en 1975 . Paralelamente, el número de personas que había agotado la ayuda para el desempleo había aumentado de 2 millones en 1974, a 4,3 millones en 1975. Sin embargo, los cálculos del gobierno generalmente infravaloraban la extensión de la pobreza, establecían por debajo de su nivel real la pobreza «oficial» y subestimaban la cantidad de desempleo. Por ejemplo, si en 1975 el 16,6\% de la población estuvo en el desempleo durante un promedio de seis meses, o el $33,2 \%$ estuvo un promedio de tres meses en el paro, la cifra media anual dada por el gobierno era del $8,3 \%$, una cifra que sonaba mucho mejor. ${ }^{13}$

13 ZINN, H., La otra historia de los Estados Unidos, Siete Cuentos, Nueva York, 2011, pp. 418-419. 
La película no aborda, en modo alguno, la pobreza como un grave problema que haya que combatir, ya no sólo como factor potencialmente criminogénico, sino desde una elemental óptica de justicia social. A quien hay que combatir, sorprendentemente, es a los pobres que son identificados, sin ambages, con los delincuentes. Y este mensaje, tan profundamente revelador, lo recibe el espectador en los minutos iniciales de la cinta. Se trata de una de las primeras escenas del filme, Paul Kersey, el protagonista, que acaba de volver de unas vacaciones en Hawái con su mujer, conversa con un compañero, Sam, y con su jefe, Henry. Hablan acerca del aumento de la delincuencia. (Esa semana se habían producido en Nueva York veintiún asesinatos). Extractamos las frases más relevantes de la conversación:

«Sam. Los «no privilegiados» nos están machacando el cerebro. Habría que meterlos en campos de concentración (...)

Henry (dirigiéndose al protagonista). ¿Qué tal sienta eso de volver a una zona de guerra después de haber estado en Hawái? (...)

Sam. Lo que necesita esta ciudad es más policías que habitantes $(\ldots){ }^{14}$

La carga ideológica del filme resulta evidente y el lenguaje empleado por los protagonistas es una muestra palmaria de ello. Para negar la existencia de la pobreza como realidad social se recurre a una manida y efectiva técnica: la manipulación del lenguaje.

En la sociedad de consumo norteamericana, reflejada en la película, no existen los pobres. Existen los «no privilegiados». El matiz es importante porque encierra una connotación despectiva, deshumanizadora, para ese colectivo, como si los pobres y los marginados mereciesen la vida que llevan. Deshumanización que se acentúa, aún más, con la propuesta de internarlos, a todos, sin distinción, en campos de concentración, obviando todo el sistema jurídico penal de garantías: abogados, fiscales, jueces, funcionarios de prisiones, legisladores... Eso sí, la respuesta punitiva siempre está presente. La ciudad se identifica con una "zona de guerra» y la solución para ganar esa guerra es dotarla de tantos policías como habitantes. Y ahí tenemos una clarísima "contradictio in terminis»: los ciudadanos de clase media-alta, encarnados por los compañeros de oficina del protagonista, teóricos adalides del neoliberalismo por su nivel de renta, y posición social, defienden, con toda crudeza, la implantación de un sistema de corte totalitario para «exterminar» a aquellos que se encuentran al margen del sistema. Tal atrocidad, nos lleva a

${ }^{14}$ WINNER, M., op. cit. 
plantearnos una serie de preguntas: ¿Cuál es el delito que han cometido los «no privilegiados»? ¿Acaso todos los pobres son delincuentes?, ¿Todos los que cometen delitos son pobres?, ¿De dónde nace esta aporofobia? Los «no privilegiados» han cometido el «delito» de nacer al margen del sistema, de ser pobres. Cierta ética protestante sostiene que los pobres son culpables de serlo y que el sistema no tiene porqué ocuparse de sus ciudadanos más allá de procurarles el acceso a la educación y a un nivel básico de asistencia sanitaria. El influyente filósofo jurídico John Rawls hace una aguda crítica de esta forma de sociedad:

«En el capitalismo del estado del bienestar, existe una considerable desigualdad en la distribución de la riqueza y de los ingresos y sólo una mínima «red de seguridad» para los pobres; suficiente para asegurar que sus necesidades básicas serán satisfechas, pero no mucho más (...) Así, puede desarrollarse una clase baja, abotargada y deprimida, cuya mayoría de miembros son dependientes crónicos de las ayudas sociales. Esta clase baja se siente fuera del sistema y no participa en el proceso político.» ${ }^{15}$

Como, certeramente, apunta Rawls, esa minoría apartada, dependiente de las ayudas sociales para sobrevivir, se siente fuera de un sistema que no le ofrece más oportunidades que una precaria subsistencia y se autoexcluye, voluntariamente, de los procesos de participación política. Por tanto, en un contexto de fuerte crisis económica y de recuperación del poder por las corrientes ideológicas más conservadoras, como el neoliberalismo, se producirá un empeoramiento, aún mayor, de las condiciones de vida de las personas más desfavorecidas lo que, irremisiblemente, abocará a un gran número de ellas a la delincuencia. La pobreza es, en consecuencia, un factor criminogénico de primera magnitud que convendría atacar para disminuir los altos niveles de delincuencia, a ella asociada, pero no criminalizando a aquellos que no tienen para comer y que han sido abandonados por el gobierno a su suerte. Estos sectores empobrecidos, al no participar en política, carecen de la capacidad de influir en ella provocando, además, la paradoja de que su exclusión les salga "gratis» a aquellos grupos de presión conservadores que, interesadamente, la provocan. Y sólo integrando a los menos pudientes se cohesionaría la sociedad, disminuirían los índices de delincuencia y aumentarían los índices de riqueza y bienestar del país. Lo contrario, seguir marginando a las clases trabajadoras, y destinando menos presupuestos para ayudar a los colectivos desfavorecidos a su inserción educativa, laboral y social es perpe-

15 RAWLS, J., «Justice as fairness: political not metaphysical», Philosophy \& Public Affairs, 1985, p. 146. (Trad. Autor.) 
tuar no sólo la desigualdad, sino también el caldo de cultivo óptimo para unos niveles de delincuencia inasumibles por la comunidad. Otra cuestión sumamente interesante, planteada en la película, es la inexistencia de un personaje concreto que encarne la figura del delincuente-tipo. A lo largo del filme, somos testigos de los avatares del protagonista y de su familia. Conocemos, también, a otros personajes tales como vecinos del barrio, policías, al inspector de éstos..., pero los delincuentes siempre aparecen como personajes sin delinear: hombres jóvenes, mayormente negros e hispanos, a veces drogados, que armados se dedican a robar y agredir a sus conciudadanos. Se ofrece, pues, una visión deshumanizada no sólo del pobre sino también del delincuente. Esa visión, parcial y sesgada, esa deshumanización del individuo facilita su posterior «eliminación» del sistema bien sea "aparcándolo», de por vida, en el sistema penitenciario, o, llegado el caso, ejecutándolo si comete algún delito castigado con la pena capital. Un elevado número de casos en que la pena de muerte fue aplicada a personas inocentes ha venido a cuestionar, muy severamente, su continuidad, pero su aplicación sigue siendo defendida, con vehemencia, por los políticos conservadores más furibundos.

Como hemos dicho, en «Death Wish» los delincuentes son seres casi anónimos. No conocemos siquiera sus nombres, no conocemos sus historias, no conocemos cómo, y porqué, sus circunstancias vitales les han conducido a dónde están. Casi no hablan, sus diálogos en la película son muy escasos. Sólo abren la boca con ánimo de dirigirse a sus víctimas, intimidarles, pedirles el dinero y poco más... Tampoco conocemos cómo viven, ni a sus amigos ni a sus familias. Estamos etiquetando a personas diferentes como si fuesen todos iguales y para el Vigilante Kersey lo son: son «no privilegiados». El maniqueísmo que deja entrever la película es evidente. Transmite al espectador una serie de ideas-fuerza sencillas y directas, fáciles de asimilar por el ciudadano medio, convenientemente "programado" por la información manipulada y recurrente que recibe de los medios de comunicación sensacionalistas. Esto último, se aprecia con claridad en la rueda de prensa del Comisario Jefe de policía Dryer. La mayoría de los periodistas parecen en ella más preocupados por encumbrar al desconocido justiciero que por que se aclaren las muertes de varios ciudadanos asesinados, por muy delincuentes que sean. No hay espacio alguno para la autocrítica, no cabe preguntarse: ¿qué hemos hecho para que la ciudad, para que los barrios se hayan convertido en lugares peligrosos e inhabitables? Los culpables son los otros, los «no privilegiados», que no tienen oficio ni beneficio, que se pasan todo el día en la calle drogándose y robando a la 
gente honrada, incluso a los mayores que no pueden defenderse, son como animales... Así son los pensamientos que afloran en la cabeza del protagonista.

\section{I.B. El miedo a la delincuencia}

Muy vinculado a la forma que se refleja ésta en los medios de comunicación (miedo al delito), puede ser empleado por el poder político y resultar útil para diversos propósitos «inconfesables»:

1. Amedrentar a las clases medias, y trabajadoras, y conseguir la implementación de medidas restrictivas de las libertades individuales y colectivas en aras a una supuesta mejora de las condiciones legales de lucha contra la delincuencia o el terrorismo (Patriot Act, por ejemplo).

2. Destinar gran cantidad de recursos públicos a programas puramente represivos, no constatados científicamente como preventivos del crimen, pero que generan gran volumen de negocio a grandes corporaciones privadas (privatización de las cárceles, gran protagonismo de la seguridad privada en la vigilancia de infraestructuras y espacios de uso público...).

3. Tampoco podemos pasar por alto que tanto la actividad delictiva, como tal, a gran escala, como la lucha contra ésta son dos grandes negocios. La delincuencia y su persecución son actividades cuantificables económicamente y de magnitudes nada desdeñables.

4. El miedo al delito es subjetivo. De hecho, el concepto de «seguridad pública» entraña un alto nivel de subjetividad. Esto se refleja en la peripecia vital del propio Kersey. No en vano, hasta que sufre el asalto en su casa, él es un hombre de principios liberales y no parece transmitir una situación de inseguridad personal significativa. La situación de inseguridad, no obstante, no va vinculada, solamente, a la alteración de la autopercepción del ciudadano por la comisión de delitos graves. De hecho, algunos delitos leves como hurtos al descuido, pequeños robos con fuerza de objetos sin excesivo valor o la sustracción de uso de vehículos a motor generan una gran sensación de inseguridad, pero, sin embargo, no revisten un serio peligro contra la integridad física de las personas. Otra cosa es la sensación de vulnerabilidad que provoca entre quienes los sufren y que es, humanamente, comprensible. 
5. Perpetuar el «statu quo» y llevar al sistema a un punto de no retorno, al no abordar la delincuencia desde una perspectiva global y no luchar efectivamente contra las causas reales que la provocan manteniendo un nivel de criminalidad lo suficientemente elevado, pero soportable, como para seguir utilizando el miedo al delito como arma política. Reiman y Leighton, expertos en sociología jurídica, son contundentes al respecto:

«En su aspecto global, la mayoría de las políticas del sistema cobran mayor sentido si las contemplamos como ingredientes de una apuesta para mantener, más que para reducir, la criminalidad. ${ }^{16}$

Un factor relevante, y muy vinculado al anterior, es el tratamiento informativo que se haga de un determinado delito, o delitos y que puede contribuir tanto a un mayor grado de alarma social respecto al mismo como a una sobrevaloración de su importancia en el conjunto de actividades delictivas perpetradas en una comunidad determinada en un período de tiempo muy concreto. En «Death Wish» el tratamiento informativo que hacen los medios es doble. Por un lado, retratan un panorama delictivo desolador, una «guerra» en la cual la policía va perdiendo, detallando cada asesinato o reyerta grave que se produce en la ciudad. Las ideas de inoperancia policial, impunidad de los delincuentes e indefensión de los ciudadanos afloran en todas las portadas. De otro, presentan al justiciero Kersey como un héroe del pueblo, reflejo de la crispación de los ciudadanos hastiados. Tienen una doble motivación: cuanta más fama obtenga el justiciero más gente se interesará por él y más ejemplares venderán los periódicos (es un interés claramente crematístico) y, también, realizando reportajes superficiales sobre su figura pueden, incluso, conseguir que otros ciudadanos sigan su estela lo que generará, a su vez, más noticias y, por consiguiente, más ingresos para los periódicos. Los medios alaban, además, a los ciudadanos que se enfrentan a los delincuentes y logran ponerlos en fuga (es el caso de la mujer mayor afroamericana que se defiende de un atracador con un alfiler de sombrero en el minuto 64 de la película). Y el tratamiento informativo tiene que ver con la forma en que se reflejan los delitos. Viendo la película, parece que la desgracia que le ocurre al protagonista es lo más normal del mundo y que los robos con agresiones mortales y violaciones están a la orden del día. Por desgracia para los guionistas, las estadísticas dibujan un cuadro totalmente distinto: la mayoría de los delitos contra la propiedad, ro-

${ }^{16}$ REIMAN, J., LEIGHTON, P., The Rich get Richer and the Poor get Prison, Pearson, Nueva Jersey, 2013, p. 4. (Trad. Autor.)

(C) UNED. Revista de Derecho UNED, núm. 23, 2018 
bos en viviendas incluidos, se cometen cuando sus propietarios se encuentran ausentes y aunque existen robos violentos, en la mayoría de los casos la violencia de los asaltantes, para con los asaltados, tiene por objeto conseguir información sobre la situación de los objetos de valor y, salvo contados casos de carácter patológico, o exceso de violencia sobrevenido, rara vez se producen muertes. Veamos, a continuación, la estadística de delitos, de Estados Unidos, de $1974,{ }^{17}$ año de producción de la película, de la que, más adelante, extraeremos una serie de conclusiones:

\section{Tabla 1}

\begin{tabular}{lcc}
\hline \multicolumn{1}{c}{ Delitos violentos } & N. $^{\text {o de denuncias }}$ & Porcentaje \\
\hline Asesinatos/Homicidios & 20.710 & $2,13 \%$ \\
Agresiones violentas & 456.210 & $46,80 \%$ \\
Violaciones & 55.400 & $5,68 \%$ \\
Atracos & 442.400 & $45,39 \%$ \\
\hline Total delitos violentos & 974.720 & $100,00 \%$ \\
\hline
\end{tabular}

Tabla 2

\begin{tabular}{lcc}
\hline \multicolumn{1}{c}{ Contra la propiedad } & N. $^{\text {o de denuncias }}$ & Porcentaje \\
\hline Hurtos & 5.262 .500 & $56,72 \%$ \\
Robos con fuerza en viviendas & 3.039 .200 & $32,75 \%$ \\
Sustracción de vehículos a motor & 977.100 & $10,53 \%$ \\
\hline Total delitos contra la propiedad & 9.278 .800 & $100,00 \%$ \\
\hline
\end{tabular}

- En ese año, fueron denunciados en los Estados Unidos 974.720 delitos violentos (contra las personas). El más numeroso, fue el de agresión con violencia, 456.210 casos denun-

17 GOBIERNO DE LOS ESTADOS UNIDOS DE AMÉRICA, «U.S. Crime Statistics». http://www.disastercenter.com/crime/uscrime.htm [fecha de consulta 5-082018]. Tablas elaboradas por el autor.

En las tablas originales, del Gobierno de los Estados Unidos, hemos advertido un error de suma en el cómputo de los delitos contra la propiedad. En el epígrafe total figura la cifra de 9.278.700 delitos, pero si sumamos los hurtos (5.262.500), las sustracciones de vehículos (977.100) y los robos con fuerza (3.039.200) obtenemos un total de 9.278 .800 delitos (100 más). La cantidad no es significativa $(0,001 \%$ del total) pero creemos conveniente realizar la observación. 
ciados, el 46,80\% de la cifra global. 20.710, fueron asesinatos y homicidios, que supondrían un $2,13 \%$ del total. A su vez, se comunicaron a la policía 55.400 violaciones, un 5,68\% del total de delitos con violencia. Se produjeron, también, 442.400 atracos objeto de denuncia, un $45,39 \%$ del total.

- Por lo que respecta a los delitos contra la propiedad, se presentaron un total de 9.278.800 denuncias, que se desglosarían de la siguiente manera: allanamiento con fines delictivos (robos con fuerza en domicilios): 3.039 .200 (32,75\%); hurto: 5.262 .500 casos $(56,72 \%$ del total); robo de vehículos (sustracción de vehículos a motor) 977.100 (10,53\% del total).

Vistas las anteriores cifras, parece claro que las agresiones y los atracos son los tipos de delitos violentos más comunes y que los asesinatos y homicidios no son tan comunes, siendo las violaciones un tipo delictivo bastante más frecuente que estos últimos, aunque sin llegar al porcentaje que suponen atracos y agresiones físicas. En lo que respecta a los delitos contra la propiedad, la mayoría son hurtos y robos con fuerza en las cosas (prácticamente el 90\% del total). El número de delitos contra la propiedad (por tanto, sin daño directo para los individuos) es más de nueve veces y media mayor que el de los delitos contra las personas. Y, de estos últimos, los más graves (asesinatos y homicidios) suponen tan sólo el 2,13\% del cómputo global.

Así pues, el robo que sufre el protagonista en su domicilio, acompañado del asesinato de su esposa y de la violación de su hija es, a la luz de las referidas estadísticas, técnicamente posible pero altamente improbable en toda su extensión. Lejos, entonces, de la pretendida habitualidad para ese tipo de delitos que quiere transmitirnos la cinta.

Lo anteriormente expuesto implica que, en nuestra opinión, los índices reales de criminalidad no se corresponden con lo reflejado en la película. Sin negar que las cifras de delitos son importantes, cuantitativamente hablando, esto no nos puede llevar a extraer las conclusiones erróneas que refleja el filme. Y ello, no porque los delincuentes sean bellísimas personas amantes de la vida humana sino porque, como resulta obvio, no es lo mismo enfrentarse a una pena por robo que a otra por asesinato y a una tercera por violación y más en un país en el cual, en gran número de sus Estados, está todavía en vigor la pena de muerte. Como señala Nicole Rafter, criminóloga y profesora de la Northeastern University de Massachusetts:

«Las películas de "vigilantes" inciden en la fuerza y propósito de la ley. La mayoría de ellas con el argumento de que necesitamos más 
leyes, en vez de controlar a esos «vigilantes», o maquillando las debilidades de nuestra sociedad, que son, en última instancia, las que engendran el fenómeno del "Vigilantismo" ». ${ }^{18}$

El tratamiento informativo de los delitos y el miedo a la delincuencia son, a nuestro modo de ver, algunas de esas debilidades a las que alude certeramente Rafter.

\section{I.C. El control de armas}

Las armas tienen un protagonismo esencial en la película: Paul Kersey se convierte en El vigilante cuando un amigo de Tucson (Arizona), el constructor Jainchill, le regala un revólver del calibre 32. Desde este momento, es como si hubiese sido investido caballero: se agravan sus enfrentamientos con los delincuentes y su existencia pasa a tener un nuevo, y casi único, sentido: mantener el orden en unas calles que él considera infestadas de indeseables. Porque Jainchill no le regala sólo la pistola le regala su ideología, su filosofía de vida:

«Jainchill. Se habla mucho del control de armas, sabe... A la mitad de la nación le asusta coger un arma como si fuese una serpiente que le mordiese a uno o algo así... Un arma no es más que una herramienta, como un martillo, un hacha... ${ }^{19}$

Lo que ocurre, es que los «indeseables» (los «no privilegiados») también portan armas. Por ello, la práctica inexistencia de diálogos entre El Vigilante y los asaltantes, (a la que hacíamos referencia cuando estudiábamos la deshumanización de la figura de los delincuentes en la cinta), se suple, en el plano narrativo, con el intercambio de disparos. Esto supone, entendemos, un salto atrás en la escala evolutiva, un canto a la idealizada autotutela que tanto satisface a los adalides del Vigilantismo. Y que nos llega, en forma de voz en off, cuando Jainchill lleva a Kersey a visitar un espectáculo que recrea una ciudad del Lejano Oeste:

«(Voz en off) La vida de los forajidos no era sino robar para comprar licor, mujeres y unas horas en una mesa de juego. Pero había otros... Soñadores que plantaron las raíces de las que creció esta gran nación. $\gg^{20}$

18 RAFTER, N., Shots in the Mirror, Oxford University Press, Nueva York, 2006, p. 156. (Trad. Autor.)

19 WINNER, M., op. cit.

${ }^{20}$ Ibídem. 
Y supone, a su vez, algo más grave: constatar, con hechos, el fracaso definitivo del complejo jurídico penal norteamericano. El fracaso, en definitiva, del correccionalismo como modelo regenerador del delincuente y el triunfo de los que abogan por la vuelta de la respuesta punitiva (que veremos en el epígrafe siguiente) y por la necesidad de defender el derecho a llevar armas como única forma de garantizar la integridad física de los ciudadanos. En este orden de cosas, a nadie puede extrañar la defensa acérrima que se hace en la cinta del uso de la violencia y del empleo de las armas para mantener el orden público. El marco legal de la tenencia de armas en los Estados Unidos ha experimentado muy pocas variaciones. Así por ejemplo, cuando el Distrito de Columbia promulgó, en 1975, la Ley de Control y Reglamentación de Armas de Fuego (Firearms Control Regulation Act) que establecía la prohibición a los residentes de poseer pistolas, armas automáticas, armas de guerra y armas no registradas y el deber de mantener en los domicilios las armas descargadas, desmontadas, o con un mecanismo de bloqueo del gatillo, el Sr. Heller, un agente de policía del Distrito, presentó un recurso que llegó hasta el Tribunal Supremo de los EE.UU. cuyos magistrados (por cuatro votos a favor y tres en contra) dictaminaron que la Ley era inconstitucional, puesto que vulneraba la Segunda Enmienda:

«La prohibición de las armas cortas y la obligación del bloqueo del gatillo de éstas (en lo relativo a la legítima defensa) viola la $S e$ gunda Enmienda. La prohibición absoluta de posesión de armas cortas en el Distrito de Columbia, en el ámbito doméstico, afecta a la totalidad de un tipo de armas que los estadounidenses eligen abrumadoramente para el ejercicio legal de la legítima defensa. Bajo todos los parámetros de escrutinio que el Tribunal ha venido aplicando para configurar los derechos constitucionales; esta prohibición, aplicada al lugar dónde la importancia de una completa protección legal de sí mismo, de la propiedad y de la familia es más acusada, podría implicar una vulneración de éstos. Del mismo modo, la obligación de que cualquier arma de fuego, legalmente autorizada, deba permanecer en el hogar desmontada, o con el gatillo bloqueado, hace imposible, en la práctica, a los ciudadanos, el uso de armas cortas con el propósito de legítima defensa y es, por lo tanto, inconstitucional.» ${ }^{21}$

21 TRIBUNAL SUPREMO DE LOS ESTADOS UNIDOS, Sentencia No 07-290. (Distrito de Columbia contra Heller, 26 de junio de 2008). https://www.law.cornell. edu//supct/html/07-290.ZS.html [fecha de consulta 28-05-2017]. (Trad. Autor.)

(C) UNED. Revista de Derecho UNED, núm. 23, 2018 


\section{I.D. La respuesta punitiva}

Lo que el Vigilantismo obvia, o parece obviar, es que una respuesta puramente represiva y que no incida en las causas reales del delito está condenada a elevar los niveles de población encarcelada hasta extremos comprometidos para el sistema. Si los pobres y desfavorecidos se ven abocados a delinquir porque carecen de medios de subsistencia y no se pone remedio a esas situaciones de pobreza y necesidad extrema acabaremos encarcelando a una parte muy significativa de los pobres de la nación, a una parte significativa que, por sexo y edad, debería constituir el sostén económico de sus respectivas familias. Esto, además provoca un efecto económico indeseable, digno de un estudio más pormenorizado: al Estado le acaba costando muchísimo más dinero mantener a una gran parte de la población encarcelada de lo que le costaría ayudarla a subsistir en su entorno familiar implementando programas de asistencia social, educación y sanidad. Bien es verdad que el dinero destinado a esos programas de orden represivo acaba engrosando los beneficios de grandes corporaciones privadas a las que se otorgan concesiones de establecimientos penitenciarios (cárceles privadas y centros de menores), vigilancia de edificios, instalaciones e infraestructuras de titularidad pública, etc.

Y qué decir del principio de resocialización del delincuente... Para el Vigilantismo la Justicia es punitiva nunca resocializadora y tampoco reparadora con respecto a las víctimas porque, más allá de la venganza y la Ley del Talión, ¿qué restauración se ofrece a una víctima cuando se ejecuta a su agresor? Los delincuentes deben ir a la cárcel y allí deben permanecer para que no vuelvan a causar daño a la sociedad. El principio de prevención específica del Derecho Penal se lleva hasta sus últimas consecuencias. Quienes cometen delitos contra la vida humana son ejecutados y la mayoría de los delitos graves llevan aparejada la cadena perpetua. La posibilidad de recuperar al delincuente para que vuelva a vivir en sociedad no es una prioridad. En el fondo se trata de una cuestión muy simple: la asignación de recursos económicos en los presupuestos del Estado. Y esta asignación está sujeta, como es lógico, a criterios políticos. Esto nos lleva a otra consideración más dolorosa. El Vigilantismo es una doctrina destinada a convencer a los ciudadanos mediante la difusión de ideas falsas, pero creíbles por no expertos, de la inutilidad de los principios sociales del estado liberal. Y esa doctrina está íntimamente vinculada al neoliberalismo que aboga por la disminución del tamaño y de las competencias del Estado. 
Ignoramos si Paul Kersey lo sabe o no, pero tomándose la Justicia por su mano está retrocediendo más de dos siglos en el tiempo, volviendo al Lejano Oeste, convirtiendo a los pequeños delincuentes en los indios contemporáneos, muertos por una buena causa: la justicia entendida como represión de los que están fuera del sistema. No creemos que ese sea un ideal sostenible y tampoco creemos que fuese el ideal de los Washington, Jefferson y Lincoln, quienes, aunque fuese desde una perspectiva elitista y burguesa, recogían el ideario de la Ilustración. El Vigilantismo no es una doctrina jurídica ni políticamente asumible: es la venganza primitiva sin alharacas, disfrazada de justicia.

\section{I.E. La organización del espacio urbano}

Una cuestión que la película refleja con verosimilitud es la relación entre marginalidad, pobreza y deterioro del espacio urbano. El deterioro del espacio urbano y sus consecuencias, no solamente criminógenas, comenzó a ser estudiado por Park y Burgess, dos grandes científicos sociales de la Universidad de Chicago que, en los años 20, desarrollaron la que se llamó Teoría Ecológica. ${ }^{22}$ Considerando a las ciudades como si fuesen seres vivos (de hecho, en cierto modo, lo son y actúan como tales) llegaron a la conclusión de que la subida del precio del suelo, en algunas zonas céntricas de éstas, lleva al progresivo éxodo de sus vecinos y a la ocupación del espacio libre por viviendas de lujo y oficinas de grandes empresas. Fábricas e infraviviendas se distribuyen por las zonas menos cotizadas, con el consiguiente deterioro y abandono del entorno. Las ciudades comienzan a desarrollarse en anillos concéntricos y las clases más acomodadas se van mudando hacia urbanizaciones de la periferia, donde viven en casas unifamiliares con jardín. Desde allí, se desplazan a sus trabajos en sus vehículos privados a través de enormes autopistas o de los sistemas de transporte público. Si bien, este último suele ser utilizado por los ciudadanos con un menor nivel de renta, que viven en los suburbios (situados en el último anillo concéntrico de la ciudad). Entonces, si el desarrollo urbanístico se deja en manos sólo de los actores privados, y sin intervención de la Administración Pública, se acaban produciendo «ghettos» en zonas de infraviviendas sobre las que, por motivos económicos, no se interviene y que quedan aisladas de vías de comunicación, y de infraestructuras comunitarias como escuelas y hospitales. Esas bolsas de pobreza y

${ }^{22}$ Vid. RAFTER, N., BROWN, M., Criminology Goes to the Movies, NYU Press, Nueva York, 2011, pp. 68-69.

(C) UNED. Revista de Derecho UNED, núm. 23, 2018 
marginación se convierten, por su propia naturaleza, en focos de criminalidad. Criminalidad que se irradia a las zonas y barrios limítrofes.

En esa década, surgen alternativas de diseño urbanístico para luchar contra la delincuencia. Arquitectos como Oscar Newman (arquitecto municipal de Nueva York) que en su obra «Defensible Space: Crime Prevention through Urban Design» (1972) aborda la implementación de estrategias C.P.T.E.D (Crime Prevention Through Environmental Design; (Estrategias de prevención del delito a través del diseño el entorno) para disminuir la incidencia del crimen en los grandes bloques de viviendas de promoción pública en los barrios y mejorar la integración social de sus habitantes.

\section{I.F. Las drogas}

Las drogas tienen en el filme un papel (aparentemente) tangencial. No se hace mención a ellas de forma directa, aunque fuesen uno de los factores más relacionados con el incremento de las tasas de criminalidad en los EE.UU. a partir de los años 60, y provocasen un elevado número de muertes entre quienes eran adictos a ellas: Como señalan Reiman y Leighton:

«La mayoría de la violencia relacionada con el tráfico de drogas tiene que ver con el hecho de que las drogas sean ilegales. Esto hace que su comercialización esté en manos de bandas y del crimen organizado $(\ldots) .{ }^{23}$

A mayor abundamiento, Wilson:

«En 1961 se produjo un repentino, y sostenido, incremento, (en el número de fallecidos por consumo de drogas en la ciudad de Nueva York) hasta las 300 personas, pero el año siguiente la cifra volvió a disminuir de nuevo. En 1963, el número volvió a incrementarse, continuadamente, y, para 1967, había alcanzado la cifra de 700 personas al año y estaba todavía aumentando. Hacia el final de la década, sobre 1.200 neoyorquinos fallecidos cada año lo habían sido por sobredosis de drogas o causas directamente relacionadas con el consumo habitual de dichas sustancias. Además, la proporción de muertes por sobredosis se incrementó mucho porcentualmente: suponía el 50\% de las muertes desde 1961 pero más del 80\% a partir de 1971.» ${ }^{24}$ ( 3 años antes de la fecha en que se desarrolla la película: 1974)

${ }^{23}$ REIMAN, J., LEIGHTON, P., op. cit., p. 38. (Trad. Autor).

${ }^{24}$ WILSON, J., op. cit., p. 6. (Traducción, y nota entre paréntesis, del autor.) 
La mayoría de los delitos cometidos en la cinta parecen tener una relación directa con el consumo de drogas:

1. El robo en el domicilio del protagonista, el asesinato de su esposa y la violación de su hija los cometen tres individuos con el único ánimo de conseguir dinero en efectivo (eso es lo que piden a las dos mujeres asaltadas, no mostrando el más mínimo interés por otros objetos de valor existentes en la vivienda). Esto nos hace presuponer que el destino último del dinero es la adquisición de estupefacientes. A refrendar esta opinión, contribuye también la actitud mostrada por los delincuentes mientras se desarrollan los hechos: están muy alterados, se comportan de forma soez y desinhibida (uno de ellos pinta las paredes con un espray que lleva encima y acaba agrediendo a las mujeres con él), actúan con escasa sangre fría, perdiendo los nervios y pegando a madre e hija. Parece obvio que comenten los delitos bajo el efecto de sustancias psicotrópicas. El resultado: un asesinato y una violación. El altísimo grado de violencia empleado, el carácter improvisado del mismo (se les ocurre sobre la marcha cuando ven a las mujeres haciendo la compra en el supermercado y sustraen su dirección del mostrador de pedidos) y el pobre botín conseguido (siete dólares con cinco centavos) ponen de manifiesto el carácter poco profesional de los asaltantes. Por todo ello, es lógico pensar que se trata de delincuentes habituales enganchados al consumo de drogas.

2. La primera víctima de El Vigilante es un recluso, en libertad condicional, adicto a las drogas. Nos enteramos de ello, en el minuto 45 de la película, por la portada del periódico que anuncia su muerte: «EX CON KILLED-REASON UNKNOWN» (EX RECLUSO ASESINADO POR MOTIVOS DESCONOCIDOS) y los informes de la policía: «Thomas Leroy Manson, en libertad condicional, había cumplido 42 meses de condena por robo, adicto a las drogas, presenta huellas de pinchazos en ambos brazos ${ }^{25}$. El titular del periódico, a pesar de su brevedad y concisión, encierra una clara justificación para la actuación de El Vigilante, desde el punto de vista del Vigilantismo: El sistema correccionalista no funciona en absoluto; los reclusos en libertad condicional siguen cometiendo delitos y, además, se relacionan con el mundo de las drogas.

${ }^{25}$ WINNER, M., op. cit. 
3. El Vigilante actúa, por segunda vez, para salvar a un ciudadano que está siendo agredido en un callejón oscuro. Sin excesivos prolegómenos, el protagonista liquida a los tres individuos que asaltaban al hombre indefenso. El presunto móvil de los hechos, deducible por el contexto, la obtención de dinero para comprar droga.

4. El Vigilante vuelve a actuar cuando está a punto de ser atracado en un vagón de metro por dos individuos. Cabe inferir que el móvil del robo es el mismo que en casos anteriores. El Vigilante dispara y mata a ambos.

5. La penúltima intervención del Vigilante se produce ya bajo un estrecho seguimiento policial y, también, en el metro. La diferencia es que en esta ocasión sufre una herida de arma blanca. El motivo de la agresión parece el mismo que en los casos anteriores: conseguir efectivo para comprar droga.

6. La última acción del Vigilante se produce en un parque. Allí se enfrenta a tres delincuentes, matando a dos de ellos y sufriendo un desmayo (ya que se encuentra herido) mientras persigue al tercero.

Observamos, pues, que casi la totalidad de los delitos cometidos en la película parecen guardar relación, siquiera indirecta, con el consumo de drogas, pero ningún responsable policial o medio de comunicación se refiere, de forma crítica, a ello.

\section{LA EVOLUCIÓN DEL PERFIL PSICOLÓGICO DEL PROTAGONISTA}

Si bien a lo largo de los diversos apartados de este artículo hemos bosquejado someramente el carácter de Paul Kersey, nos parece oportuno profundizar en los rasgos de su personalidad y ver cómo esta se va matizando a medida que avanza la cinta. Debemos para ello hacer hincapié en una serie de consideraciones:

1. Paul Kersey se ha convertido, él mismo, en un asesino. Un asesino con la coartada moral que le da invocar su necesidad de defenderse a sí mismo, como hicieron los pioneros. Aquellos que, para él, hicieron grande a su país, que portaban armas para defenderse y que no tenían que hacer frente a un montón de subterfugios legales para el ejercicio de sus derechos. 
2. Kersey no es un demente, cree que su forma de actuar tiene una base jurídico-filosófica: está en la segunda enmienda de la Constitución, está en el ADN de su nación: mata o muere, es sencillo. Todo lo demás es favorecer al delincuente.

3. El personaje protagonista tampoco parece atravesar la fase de duelo. Ha sufrido un durísimo golpe y, tras una breve y natural depresión, lo único que elabora es la venganza. Lo cual es humanamente comprensible, pero se hace enfermiza en el sentido de que la venganza por un asesinato debería agotarse en la muerte de los culpables de éste. Sin embargo, el justiciero Kersey da un paso, patológico, más allá, y pretende vengarse de todos los delincuentes potenciales que con él se crucen arrogándose, motu proprio, el papel de justiciero vengador universal: El Vigilante.

4. Frente a la posición «dura», que defiende el protagonista, encontramos la posición «tibia», que representaría el personaje de su yerno, Jack, quien se nos muestra como un hombre apocado, incapaz de reaccionar ante el sufrimiento provocado por los delincuentes a su esposa, con una personalidad excesivamente «almibarada» y que llama «papá» a su suegro. Encarna a una persona sobrepasada por las circunstancias, que no reacciona ni hace frente a la adversidad. Es la caricatura de un «liberal». El contrapunto entre ambos es evidente. En la piel de Jack, Kersey aparece caracterizado, por simple contraste, como su «alter ego»: la esencia del Vigilantismo; un hombre fuerte y decidido que toma la iniciativa. Así se ve, con claridad, en esta conversación entre ambos al salir de visitar a Karol, hija de Kersey y esposa de Jack, en el sanatorio de Long Island donde recibe tratamiento:

«Jack. De haber sido inteligentes para vivir en el campo...

Kersey. ¿Y qué hay de la vieja costumbre americana de la defensa propia? Si la policía ya no nos defiende ¿por qué no nos defendemos nosotros?

Jack. Ya no somos pioneros, papá.

Kersey. ¿Y qué somos Jack? ¿Qué llamas tú a aquellos que enfrentados a una situación que los asusta tratan solo de no pensar?

Jack. ¿Civilizados?»26

26 Ibídem. 
5. El mensaje, y su carga de profundidad ideológica, resultan obvios: los hombres blandos e incapaces de defender a sus familias sucumben fácilmente ante los criminales que campan a sus anchas por las calles, mientras las autoridades no hacen nada al respecto. El protagonista denuncia ante un agente lo que le ha ocurrido (han asesinado a su mujer y violado a su hija: dos delitos muy graves) y el policía que lo atiende no le da demasiadas esperanzas, está acostumbrado a un altísimo número de delitos e insensibilizado por ello: «En esta ciudad las cosas son así...» La policía los detiene, pero salen inmediatamente en libertad («entran por una puerta y salen inmediatamente por la otra»).

6. Tras este cúmulo de desgracias, el protagonista sufre un primer atraco, defendiéndose del asaltante con un calcetín que había rellenado de monedas de veinticinco centavos. Sale victorioso del envite y eso le provoca cierta euforia. Se ha defendido a sí mismo y el delincuente ha huido. Tan sólo le ha propinado un buen golpe. Nadie ha resultado herido.

7. Kersey se convierte en El Vigilante, al volver de Tucson, y sufrir un segundo atraco mientras paseaba por el parque. Mata a un ex recluso, drogadicto y en libertad condicional. La prensa se hace eco de la noticia. Tras unos primeros momentos de sobresalto e incredulidad, va asumiendo su papel como «justiciero del pueblo». No dejan de repetirse los enfrentamientos armados con otros delincuentes y la prensa encuentra en el vengador anónimo un filón propagandístico (no sólo aumenta la venta de ejemplares de periódicos, sino que el sensacionalismo mediático permite añadir más confusión al debate que se plantea en la ciudad), El Vigilante se ve cómodo en su papel y acepta su nueva «responsabilidad» como garante de la ley y el orden en el barrio.

8. Se suceden las actuaciones del Vigilante, los delitos parecen disminuir milagrosamente lo que, unido a la popularidad que la prensa le está otorgando, pone a la policía en una situación muy incómoda, dado que su incompetencia para detener al Vigilante va pareja con la demostrada, antes de la aparición de éste, para perseguir los delitos y detener a los delincuentes. Ante esta difícil tesitura, que pone en peligro su puesto y su prestigio profesional, el jefe de la policía ordena a sus mejores hombres abrir una investigación a fondo. Dar con paradero del Vigilante, se convierte en la prioridad de todos los policías de la ciudad. Entretanto, el Vigilante se ha convertido en un 
héroe popular, que atrae la simpatía de la gente al haber conseguido que los delincuentes se encuentren amenazados y ya no actúen con impunidad.

9. Después de numerosas y complicadas indagaciones la policía descubre la identidad del misterioso justiciero, se trata de Paul Kersey, el arquitecto que había denunciado el asesinato de su esposa y la violación de su hija. El inspector de policía Frank Ochoa va a visitarle al Hospital, dado que ha resultado herido en uno de sus enfrentamientos armados con delincuentes. Después de una tensa conversación entre ambos, y como "penitencia», al reconocer entre líneas su propia incompetencia, el inspector de policía ofrece a Kersey no detenerle si se va de la ciudad y deja de actuar. No es un ofrecimiento gratuito, el jefe de policía sabe que el supuesto éxito profesional que supondría conseguir detener al justiciero se vería más que empañado cuando gran parte de los ciudadanos, que lo ven como un héroe, lo criticasen: «resulta que la policía es incapaz de poner orden en la ciudad, pero, por lo visto, si logran detener al único hombre que les hacía el trabajo».

10. Así pues, el policía renuncia con su conducta a aplicar cualquier atisbo de ética profesional: es capaz de dejar libre a un asesino con tal de no ver mermado su prestigio. El personaje demuestra elevadas dosis de ambivalencia puesto que, en el fondo, comparte objetivos con el Vigilante.

Se supone que el inspector debe hacer su trabajo conforme a la ley, pero como esa ley es, precisamente, la que le impide hacerlo bien (en su opinión), no ve impedimento alguno en saltársela para liberar a un asesino que, en el fondo, ha hecho, saltándose también la ley, ese mismo trabajo. La diferencia es que el vigilante Paul Kersey hace su trabajo sembrando la ciudad de cadáveres. Y el inspector de policía Ochoa entiende, o parece entender, que todo eso nos son más que daños colaterales, perfectamente asumibles en la cotidianeidad de la gran urbe moderna.

11. Si aquellos que presumen de ser garantes del sistema y pilar de la democracia se convierten en voceros sensacionalistas, entonces... ¿qué garantías puede tener un ciudadano de una minoría étnica que viva en un barrio marginal y sea detenido injustamente o por error si no puede acudir a una prensa independiente para denunciar su situación? Aún hoy, y por desgra- 
cia, son muy frecuentes los casos de malos tratos y detenciones arbitrarias de la policía estadounidense y gravísimos los disturbios que provocan estas formas de actuar en las ciudades. (Son célebres el caso de Rodney $\mathrm{King}^{27}$ en la ciudad de Los Ángeles y el más reciente el de los incidentes en la ciudad de San Luis en el Estado de Missouri).

\section{EL MISTERIO DE LOS PERSONAJES AUSENTES}

1. Una figura que se obvia en la película es la de los jueces. No creemos que se trate de un olvido inconsciente, sino que refleja una dura crítica a los principios básicos del Estado de Derecho. Los jueces no están presentes porque la película es una andanada directa a los principios de la justicia liberal y el Vigilantismo entiende el proceso judicial no como una garantía de las libertades de los ciudadanos, sino como un trámite prescindible: quién delinque merece un castigo y ese castigo debe serle aplicado de forma inmediata, sin dilaciones, sin posibilidad de que se defienda, de que se explique. Si has cometido un delito eres culpable y punto. Las circunstancias atenuantes o eximentes, el que se haya podido delinquir bajo el efecto de las drogas o el alcohol, por ejemplo, o el hurto famélico no son consideradas en modo alguno. La única aparición de un personaje vinculado al mundo jurídico es la del Sr. Peters, Fiscal del Distrito, al que visitan el Inspector Jefe Dryer y el Comisario Ochoa, para mostrarle la sangre de Kersey en la navaja con la que ha sido herido. Fiscal, Inspector Jefe y Comisario se compinchan para no detener a Kersey. Las agresiones callejeras han bajado, de 950 a 470, en una semana lo que supone que el trabajo del Vigilante ha sido efectivo y ha conseguido disminuir la delincuencia. Reconocer su éxito podría entrañar que se multiplicasen los seguidores del vigilante en las calles.

2. Otro personaje ausente de la película es el que encarnaría a los políticos, quienes, a fin de cuentas, y elegidos por el pueblo, son los responsables de articular las políticas que lleven al bien común y al bienestar de los ciudadanos. No aparece ninguno en el filme. Esta omisión, una suerte de «damnatio memoriae», tiene que ver con el elevado grado de desconfianza que suscitan a los ciudadanos sus representantes, a quienes identifican con los ricos y poderosos. Boggs

${ }^{27}$ Vid. KASINSKY, R., "Patrolling the Facts: Media, Cops and Crime. The Rodney King Beating», en Media, Process and the Social Construction of Crime, coord. Gregg Barak, Routledge, Nueva York, 1995, pp. 221-226. 
y Pollard, profesores de la National University, en San Diego (California), lo expresan así:

«La sociedad americana contemporánea está inundada por una gran variedad de símbolos, imágenes, códigos y eventos que, tarde o temprano, vienen a dominar el paisaje político, distorsionando temas y discursos de una manera que puede beneficiar sólo a una ya bien arraigada cadena de intereses privilegiados. El avance de la colonización empresarial de la política queda así sólo débilmente cuestionado, en el mejor de los casos, en un entorno donde grandes homenajes a estas ideas turbias, tales como populismo, diversidad, identidad política y multiculturalismo, resultan ser tan sólo otra excusa para una posmodernidad amorfa y para el localismo.» ${ }^{28}$

3. Tampoco se hace mención a ningún centro penitenciario ni aparece recluso alguno cumpliendo con su pena de privación de libertad. El mensaje inconsciente de la película es intencionadamente demoledor: el complejo político-jurídico-penal simplemente no existe. Los pobres ciudadanos honrados son víctimas inocentes y tienen que defenderse solos si no quieren perecer. Volvemos otra vez a la imagen del Lejano Oeste en el que los primeros colonos estaban a merced de los «malvadísimos» nativos norteamericanos. Rara vez, el Séptimo de caballería les sacaba las castañas del fuego. En la película, el Séptimo de caballería es la policía que nunca está cuando debe y cuando está es para detener al justiciero Kersey, ante la incomprensión de parte de sus ciudadanos. Así pues, en una película en que no aparecen políticos, ni jueces ni abogados ni cárceles y donde los delincuentes vienen a representar un personaje "coral» puesto que son todos iguales, como los indios en los westerns clásicos, la atención se centra exclusivamente en su protagonista: Paul Kersey, un arquitecto de ideas liberales que lleva una vida acomodada y que sólo toma consciencia, de repente, de los graves problemas de la sociedad cuando la desgracia se ceba con él y con su familia. Ese es su Camino de Damasco y ahí es dónde «San» Paul Kersey se cae del caballo y ve la luz del Vigilantismo.

\section{CONCLUSIONES}

1. La película plantea muy bien la fractura en la transición desde el sistema penal del correccionalismo, inspirado en principios resocializadores (Garland) al sistema penal neoliberal centrado en el incremento de la fuerza de la respuesta punitiva. Y esta transición ha

${ }_{28}$ BOGGS, C., POLlARD, T., A World in Chaos, The Rowman \& Littlefield Publishing, Lanham, Maryland, 2003, p. 246. (Trad. Autor.)

(C) UNED. Revista de Derecho UNED, núm. 23, 2018 
sido tan oscura y tan brutal como los escenarios de los barrios degradados que presenta la película. El retrato que se hace del papel del Estado en la lucha contra la delincuencia también es demoledor. Comisarías destartaladas, con pocos policías que, saturados de trabajo, se ven incapaces de atender al ciudadano. Innumerables delincuentes que desfilan por ellas con una familiaridad inusitada (rateros y prostitutas). Si los propios agentes del sistema penal no creen en él ¿cómo puede siquiera plantearse su continuidad en los mismos términos?

2. Otra de las ideas-fuerza de la película: la política criminal liberal favorece al delincuente y perjudica a los ciudadanos honrados. Este axioma, además de enormemente reaccionario, es radicalmente falso. Sabemos que no es así y que la mayoría de la población penitenciaria está compuesta por individuos afroamericanos o hispanos jóvenes y de clase trabajadora.

3. La cinta, además de retratar el fenómeno delincuencial desde una óptica sesgada, no ofrece soluciones plausibles a la crítica situación que expone. Más allá de un canto a la respuesta punitiva como único remedio, no se detiene en analizar ni en proponer alternativas. tismo:

4. El filme refleja muy bien la esencia y los valores del Vigilan-

a) La exaltación del derecho a la legítima defensa, mediante el empleo de armas de fuego, principalmente, cuando los individuos entiendan que el Estado no les protege (a ellos o a sus familias) adecuadamente. Esta cuestión entraña un elevado grado de subjetividad y, con ello, grandes posibilidades de que se produzcan extralimitaciones graves en el ejercicio de ese derecho.

b) La respuesta punitiva como elemento clave de la lucha contra el delito, obviando todo tipo de alternativas y políticas resocializadoras del delincuente que son consideradas ineficaces y gravosas para la comunidad. El castigo se convierte en un fin en sí mismo, una suerte de venganza institucionalizada.

c) El análisis simplista de la realidad social y del entorno criminal, sin profundizar en las causas últimas del hecho delictivo tales como la pobreza, la adicción a las drogas, la falta de oportunidades o la discriminación racial y étnica.

d) La visión neoliberal del sistema jurídico penal, que pasa a convertirse en un conglomerado de instituciones público-priva- 
das gestoras de elevados presupuestos que acaban empleándose en costosos programas de lucha contra la delincuencia cuyos resultados no consiguen disminuir los niveles de criminalidad. Esos presupuestos acaban engordando los beneficios de numerosas empresas privadas.

\section{BIBLIOGRAFÍA}

\section{Obras y artículos}

Boggs, Carl., Pollard, Tom. A World in Chaos. Lanham, Maryland, The Rowman \& Littlefield Publishing, 2003.

Culberson, William. Vigilantism: Political History of Private Power in the United States. Nueva York, Greenwood, 1990.

Dilulio, John. "Rethinking Crime-Again», Democracy: A Journal of Ideas n. ${ }^{\circ} 16,2010$. Accedido 14 de mayo de 2017. http://www. democracyjournal.org/16/6739.php

GaRLAND, David. La cultura del control. Barcelona, Gedisa, 2005.

Kasinsky, Renée «Patrolling the Facts: Media, Cops and Crime. The Rodney King Beating», en BARAK, Gregg. Media, Process and the Social Construction of Crime. Nueva York, Routledge, 1995.

KLEIMAN, Mark. When Brute Force Fails. Washington, NCJRS Departamento de Justicia. Gobierno de los Estados Unidos de América, 2005. Accedido 21 de agosto de 2018. https://www.ncjrs.gov/ pdffiles1/nij/grants/211204.pdf

LENZ, Timothy. «Conservatism in America Crime Films», Journal of Criminal Justice and Popular Culture, n. ${ }^{\circ}$ 12, 2005.

Mc Kenna, Tony., Art, Literature and Culture from a Marxist Perspective, Londres, Palgrave Macmillan, 2015.

RAFTER, Nicole. Shots in the Mirror. Nueva York, Oxford University Press, 2006.

Rafter, Nicole., Brown, Michelle. Criminology goes to the Movies. Nueva York, NYU Press, 2011.

RAwLS, John. «Justice as fairness: political not metaphysical», Philosophy \& Public Affairs, 1985.

Reiman, Jeffrey., Leighton, Paul. The Rich get Richer and the Poor get Prison. Nueva Jersey, Pearson, 2013. 
Rosenbaum, Jon., Sederberg, Peter. «Vigilantism: An Analysis of Establishment Violence», Comparative Politics, n. ${ }^{\circ}$ 4, 1974.

Wilson, James., Thinking about Crime. Nueva York, Basic Books, 2013.

Winner, Michael., Death Wish. Los Ángeles, Paramount Pictures, 1974.

ZINN, Howard. La otra historia de los Estados Unidos. Nueva York, Siete Cuentos, 2011.

\section{Jurisprudencia y legislación}

Estados Unidos de América. Constitución de los Estados Unidos de América. Instituto de Información Legal. Facultad de Derecho de la Universidad de Cornell, Ithaca (Nueva York). Accedido 12 de mayo de 2017. https://www.law.cornell.edu/constitution/second_ amendment

Tribunal Supremo de los Estados Unidos. District of Columbia et al. v. Heller. No 07-290. 26 de junio de 2008. Fundamento Jurídico 3. ${ }^{\circ}$. Accedido 28 de mayo de 2017. https://www.law.cornell.edu/supct/ html/07-290.ZS.html

\section{Enciclopedias jurídicas en la red}

West's Encyclopedia of American Law. Segunda edición. Accedida 20 de agosto de 2018. https://legal-dictionary.thefreedictionary.com/ Vigilantism

\section{Páginas web}

Gobierno de los Estados Unidos de América. U.S. Crime Statistics. http://www.disastercenter.com/ [accedida 5 de agosto de 2018]. 